\title{
A SALA TÁ ON: O ENSINO REMOTO DE FILOSOFIA NA EDUCAÇÃO SUPERIOR EM TEMPOS DE PANDEMIA
}

\author{
1Tamara Cristina Bastos Santos, ${ }^{2}$ Klisman Lucas de Sousa Castro, ${ }^{* 3}$ Luciano da Silva Façanha, \\ ${ }^{4}$ Sansão Hortegal Neto, ${ }^{5}$ Francyhélia Benedita Mendes Sousa, ${ }^{6}$ Lídia Cristina Costa Nunes, \\ ${ }^{7}$ Elayne de Araujo Pereira, ${ }^{8}$ Irlene Veruska Batista da Silva and ${ }^{9}$ Cláudia da Silva
}

${ }^{1}$ Mestra em Cultura e Sociedade pela UFMA. Bacharel em Comunicação Social com habilitação em Jornalismo pela Faculdade Estácio de São Luís-MA; ${ }^{2}$ Mestre em Cultura e Sociedade pela UFMA. Membro do GEPI Rousseau UFMA. Graduado em Filosofia pela UFMA; ${ }^{3}$ Doutor em Filosofia pela PUC-SP. Docente Associado do Departamento de Filosofia e do quadro permanente do Programa de Pós-Graduação em Cultura e Sociedade da UFMA; ${ }^{4}$ Mestrando do Programa de PósGraduação em Cultura e Sociedade da UFMA. Graduado em Comunicação Social, Habilitação Rádio e TV; ${ }^{5}$ Mestranda em Cultura e Sociedade - UFMA. Licenciada em Filosofia pela UFMA. Membro do GEPI Rousseau UFMA. Bolsista da FAPEMA; ${ }^{6}$ Mestranda em Cultura e Sociedade - UFMA. Graduada em Letras pela Faculdade Pitágoras do Maranhão; ${ }^{7}$ Mestranda em Cultura e Sociedade - UFMA. Graduada em Filosofia pela Universidade Federal do Maranhão. Pesquisadora do GEPI Rousseau UFMA; ${ }^{8}$ Mestranda em Cultura e Sociedade - UFMA. Graduada em Filosofia pela Universidade Federal do Maranhão. Membro do GEPI Rousseau UFMA; ${ }^{9}$ Mestranda em Cultura e Sociedade - UFMA. Graduada em Filosofia pelo IESMA. Membro do GEPI Rousseau UFMA

\section{ARTICLE INFO}

\section{Article History:}

Received $06^{\text {th }}$ February, 2021

Received in revised form

$11^{\text {th }}$ March, 2021

Accepted $28^{\text {th }}$ April, 2021

Published online $30^{\text {th }}$ May, 2021

\section{Key Words:}

Remote Teaching; Philosophy Teaching;

Digital Technologies; Pandemic.

*Corresponding author:

Luciano da Silva Façanha,

\begin{abstract}
The year 2020 was marked by the viral disease called the new coronavirus or covid-19. A lethal disease with a high degree of proliferation and contagion in which social isolation and distancing are the forms of palliative prevention to contain the mass advance of the virus. Educational institutions were closed to decrease human contact and most of them adhered to the remote teaching format. As a whole, the covid-19 pandemic modified the traditional classroom format and caused teachers and students to exchange the board and portfolios for the digital screen. It took a new adaptation and reinvention of the teacher, his didactic structure and his teachinglearning process. The objective of this work goes in this direction, to understand the current scenario of remote teaching and how philosophy teachers of higher education in Maranhão are dealing with the online class format and what digital resources/technologies have used in the virtual classroom.
\end{abstract}

Copyright (C) 2021, Tamara Cristina Bastos Santos et al. This is an open access article distributed under the Creative Commons Attribution License, which permits unrestricted use, distribution, and reproduction in any medium, provided the original work is properly cited.

Citation: Tamara Cristina Bastos Santos, Klisman Lucas de Sousa Castro, Luciano da Silva Façanha, Sansão Hortegal Neto, Francyhélia Benedita Mendes Sousa, Lídia Cristina Costa Nunes, Elayne de Araujo Pereira, Irlene Veruska Batista da Silva and Cláudia da Silva, 2021. "A sala tá on: o ensino remoto de filosofia na educação superior em tempos de pandemia”, International Journal of Development Research, 11, (05), 47333-47338.

\section{INTRODUCTION}

Apandemia trouxe novos moldes para a educação, principalmente à esfera educacional do ensino superior. O colegiado formado por docentes e discentes trocaram emergencialmente a vivência presencial pela vivência virtual. A nova sala de aula passou a ser o intermeio frequente desses dois públicos e possibilitou um novo dinamismo por parte dos educandos e vice-versa. Foi na China, na cidade de Wuhan em dezembro de 2019, que apareceu a primeira notificação de um surto viral letal. Desde esse tempo o mundo segue as notícias e a rapidez com que a enfermidade invade e se expande para diversos países; além do caos no sistema de saúde que vem sofrendo colapsos, motivado pelo progresso dos casos a nível mundial de contágio por transmissão comunitária. Diante da gravidade do momento a Organização Mundial da Saúde (OMS) decretou estado de pandemia, no dia 11 de março, e intensificou as medidas protetivas de segurança sanitária. Com isso, desde março de 2020 as tarefas pedagógicas presenciais foram suspensas devido à situação de pandemia no Brasil e no mundo. Essa foi uma das inquietações que motivaram levar esse trabalho adiante e entender os impactos na vida do professor do curso supracitado. Destarte refletir sobre essas questões que interferem ativamente nas políticas educacionais e na vida das pessoas é de suma importância diante desse momento de crise mundial. $\mathrm{O}$ ensino remoto desde o ano de 2020 é uma realidade para muitas universidades públicas de vários estados brasileiros. Plataformas de ensino à distância, como Google 
Meet, Zoom ou demais, se configuram como aliadas desse processo do ensino-aprendizagem, dessa forma, no Maranhão as três principais instituições públicas, não fugiram dessa realidade, e adotaram formas e maneiras de ensinar mesmo diante das dificuldades que o contexto pandêmico oferece. $\mathrm{O}$ alvo desta pesquisa são os professores de Filosofia vinculados às Universidades Federal (UFMA); Estadual (UEMA) e o Instituto Federal do Maranhão (IFMA). O objetivo é o de compreender como esses docentes estão encarando esse momento, que ferramentas de ensino remoto utilizam e as percepções que se estabeleceram diante desse formato de aula. Este trabalho de cunho qualiquanti discorre acerca das conjecturas dos educandos, bem como a frequência com que utilizam as tecnologias digitais, o cenário como enfrentam o ambiente de estudos e o rendimento acadêmico; e como a aprendizagem consegue chegar aos discentes neste momento frente às circunstâncias demandadas, com as aulas remotas. Participaram da pesquisa 11 professores dos cursos de Filosofia distribuídos nessas três instituições, que responderam um questionário composto de 10 perguntas sendo objetivas e discursivas expressando suas concepções e ambientação com a aula on-line. Os dados coletados foram analisados conforme as questões elencadas no questionário. Dessa forma, as seções seguintes abordam os desdobramentos desse momento e discorrem sobre a pandemia, o uso das tecnologias diante desse período, a relação dos professores de Filosofia com o contexto atual e os desafios no processo de ensino-aprendizagem virtual.

Educação e pandemia: O ano de 2020 foi marcado pela enfermidade viral denominada de novo coronavírus ou covid-19. Uma doença letal e com alto grau de proliferação e contágio em que o isolamento social e o distanciamento são as formas de prevenção paliativa para conter o avanço em massa do vírus. Instituições educacionais foram fechadas para diminuir o contato humano e grande parte delas aderiu ao formato de ensino remoto. O novo modelo foi autorizado em portaria pelo Ministério da Educação (MEC) em 17 de março de 2020, em que dispôs sobre a substituição da aula presencial em meios digitais enquanto durar a pandemia. Seguindo essa lógica outro órgão competente da instância educacional, o Conselho Nacional de Educação (CNE), concedeu parecer favorável e regularizou a utilização das aulas remotas, em 28 de abril do ano passado. Houve um esforço conjunto para reorganizar o calendário escolar e a computação das tarefas não presenciais para cumprimento da carga horária mínima anual, em razão da covid. Sendo assim, a proposta foi deferida pelo MEC um mês após, em 29 de maio de 2020. Professores, alunos e pais tiveram que se adaptar urgentemente em meio ao modelo virtual de ensino. Apesar da regularização das aulas on-line pelo MEC, a sociedade escolar não estava preparada para imersão neste espaço virtual. Isso porque parecia uma realidade distante diante de um modelo de educação integralmente presencial. A readaptação dos sistemas educacionais, corpo docente e discente tiveram que se moldar rapidamente a esse tipo de ensino. A transposição dessa mudança repentina desencadeou uma linguagem diferente diante da qual os docentes estavam acostumados, isso diz respeito à presença significativa do professor em sala de aula, o contato, o toque, o olho no olho; comportamentos tangíveis que a sala de aula virtual não proporciona. Sobre esse assunto Kenski (2004) atesta que ambos, professores e alunos precisam construir uma nova linguagem para manter e fortalecer o diálogo no ensino remoto.

Estudantes e professores tornam-se desincorporados nas escolas virtuais. Suas presenças precisam ser recuperadas por meio de novas linguagens, que os representem e os identifiquem para todos os demais. Linguagens que harmonizem as propostas disciplinares, reincorporem virtualmente seus autores e criem um clima de comunicação, sintonia e agregação entre os participantes de um mesmo curso. (KENSKI, 2004, p. 67)

Os desafios existem e o professor precisa adotar outras habilidades para além do manuseio com a tecnologia, que nesse caso, é o uso da criatividade para fixar a atenção dos alunos e abusar dos recursos tecnológicos para dinamizar as aulas. Essas ferramentas são os vídeos, as apresentações imagéticas como roteiro da aula expositiva, os aplicativos referentes ao assunto ministrado e as mídias digitais como ferramentas complementares no processo de ensino- aprendizagem. Uma das frases corriqueiras mais citadas por professores são: "não estou acostumado a lidar com essas tecnologias", relatos que demonstram os desafios diários e a necessidade presente de uma revolução educacional mediada pelas ferramentas e aparatos tecnológicos. Isso demonstra a urgente readaptação do docente nessa crescente construção dessa realidade e a aptidão para acompanhar os avanços da sala $\mathrm{ON}$. A reconfiguração do contexto escolar coloca em ênfase não a necessidade em usar a qualquer custo esses recursos, mas acompanhar o reflexo das formas institucionais, as mentalidades e a cultura educacional desse novo professor e novo aluno que de maneira performática muda de papel e passa a se aprofundar nesse meio, conforme tese do teórico Lévy (2005). O contexto pandêmico ofereceu uma oportunidade de remodelar o ensino, ou seja, os professores que tinham pouco ou nenhum contato com tecnologia precisaram planejar as aulas mediadas por telas digitais. Outros estorvos diante desse cenário passaram a surgir, como problemas com a estabilidade do Wi-fi, envolvimento dos alunos com os conteúdos dentre outras problemáticas.

Lado a lado: Ensino e Tecnologia: A etimologia do termo tecnologia torna-se bem-vindo neste trabalho à medida que a proposta lança luz sobre o termo e confere a ele sentido. Tecnologia é um recurso da ciência e da engenharia que oferece instrumentos, métodos e técnicas visando a resolutividade de problemas. A combinação do termo com a educação refere-se ao emprego dessas ferramentas para aperfeiçoar o ensino, ou seja, usar a tecnologia a favor da educação, fomentando o avanço socioeducativo dos discentes e dessa forma, melhorando constantemente $\mathrm{o}$ acesso à informação $\mathrm{e}$ ao conhecimento. Entre esses recursos inúmeros são os que proporcionam benefícios ao ensino-aprendizagem, como as redes e mídias digitais que podem ser utilizadas como métodos para o aprendizado. Nessa perspectiva o uso dos suportes tecnológicos deve ser visto na concepção de uma metodologia de ensino, proporcionando a interação digital dos estudantes e possibilitando o engajamento com os esquemas mentais a partir do raciocínio lógico tendo a tecnologia como mediação desse processo. Diversos estudos que remetem a essa área ratificam a aplicação das tecnologias como metodologias ativas que acionam de forma mais eficaz e autônoma, com o intuito no crescimento contínuo dos educandos nas variadas vertentes destinadas para a realidade a qual se vivencia, principalmente o contexto recente de pandemia.

Isso se confirma quando a comunicação intermediada por esse meio, de acordo com Quintas Mendes, possibilita:

Apresentar uma coloração socioemocional muito forte, em muitos aspectos não inferiores à comunicação face-a-face, sendo bastante favorável à criação de comunidades de aprendizagens com relações sociais fortes e desempenhos de tarefa comparáveis à comunicação presencial (QUINTAS-MENDES et al, 2010, p. 258).

Com isso, admite-se que o uso da tecnologia é uma realidade presente na sociedade escolar, de alguma forma a pandemia proporcionou rapidamente esse novo formato. Os recursos enriquecem o intercâmbio dos alunos com o conhecimento e permitem que possam expressar o que aprendeu tornando-se protagonista do processo de aprendizagem. A necessidade de adoção dessas ferramentas justificase em um dos trabalhos do autor Bottentuit Júnior (2019, p. 19):

[...] As tecnologias digitais ao ocuparem um espaço na vida dos jovens deverão ser integradas às metodologias ativas, como fonte de consulta a materiais, para realização de tarefas ou simplesmente um canal de comunicação entre professor-aluno e aluno-aluno. Muitas delas já oferecem a plataforma ideal para a organização didática e ao explorarem o som, o vídeo, a imagem e a animação terminam por atrair a atenção e favorecer uma aprendizagem mais contextualizada, atualizada e lúdica.

Talbert (2019) alerta para a necessidade de ativar novos modelos de aprendizado, e isso diz respeito a se desvencilhar do "modelo 
tradicional", que institui 'dependências intelectuais indesejadas dos alunos em relação aos professores". Diante do atual momento é necessário, segundo Bottentuit Junior (ibidem) que os jovens discentes criem, recriem e repensem os problemas colocados diante deles por meio das tarefas diárias em resoluções planejadas que podem contribuir com a capacidade crítica e reflexiva do aluno. E isso se confirma com o uso de metodologias ativas e da tecnologia.

Por que então permitir que a tecnologia e a educação caminhem lado a lado nesse processo do saber? O teórico Bottentuit Junior (ibidem) alega que:

[..] É inegável, afirmar que todas as áreas do conhecimento se beneficiaram com o aparecimento das tecnologias móveis e, sendo a educação um dos principais pilares sociais, também tirou ou deveria ter tirado seu partido, permitindo ao aluno e ao docente o acesso a um conjunto amplo de recursos informacionais importantes, e necessários, às suas formações. (p.16).

Dessa forma, em tempos de pandemia esses suportes/auxiliares tecnológicos em sala de aula além de ajudar no aprendizado motivam os alunos e professores a continuarem nesse processo educacional mesmo que remoto e à distância, com o propósito de cooperar com os entes do ensino, se mantendo conectados e interagindo entre si oferecendo harmoniosa convivência virtual, pois além dos conteúdos ministrados, o diálogo, o engajamento e a criatividade tornam-se elementos essenciais diante desse momento conturbado e adverso.

Professores de Filosofia $\mathbf{x}$ tecnologias digitais: Como demonstrado na seção anterior, a pandemia causada pelo covid-19 exigiu dos professores uma mudança na forma de ensinar. É verdade que em muitas instituições, em especial as particulares, a aprendizagem em EAD é realidade há bastante tempo. Contudo, o choque motivado pelo cenário epidêmico exigiu uma mudança abrupta dos docentes que estavam familiarizados somente com a perspectiva espacial tradicional de ensino, o que redefiniu as abordagens didáticas. Sendo assim, é importante entender como os docentes de filosofia repercutiram os instrumentos utilizados pela disciplina para o ensino remoto. Nesse caso, a própria reflexão filosófica exige múltiplos olhares, ou seja, o entendimento vasto sobre a conduta a ser adotada em sala de aula. De acordo com Cerletti (2009), a prática docente conta com um panorama variado de condicionamentos e influências, é uma representação complexa que está atravessada por várias questões, e as tarefas acadêmicas são selecionadas com base em exigências que garantem a continuidade e funcionalidade institucional. Além disso, compreende-se que: "O exercício filosófico é assim um exercício de desestabilização, de saída da falsa segurança na opinião e de mergulhar no caos do não pensamento para, pensando, produzir equilíbrios possíveis, sempre instáveis, sempre dinâmicos" (GALLO, 2012, p. 25). Nesse sentido, a atividade docente em filosofia permite que reflexões e críticas sejam construídas, e possam contribuir para novos hábitos institucionais.

Levando em consideração tais argumentos, é necessário compreender que a prática docente filosófica não somente faz uso das novas dinâmicas tecnológicas, mas também se debruça a entendê-las. A tecnologia permite que as fronteiras geográficas sejam derrubadas, e estabeleça inovadoras possibilidades de comunicação entre os homens: "[...] implica que todos somos levados a pensar, de modo mais ou menos sistemático e duradouro, sobre a sua presença na nossa vida" (CUPANI, 2016, p. 11). Dessa maneira, a tecnologia não é encarada apenas do ponto de vista materialista, isto é, da perspectiva como objeto, mas como sistema, processo e procedimento. Levando em conta esse entendimento e a relação com a docência em filosofia, percebe-se que:

Criar condições de ter uma participação mais ativa dos alunos implica, absolutamente, a mudança da prática e o desenvolvimento de estratégias que garantam a organização de um aprendizado mais interativo e intimamente ligado com as situações reais. Por isso, a inovação na educação é essencialmente necessária. A inovação é uma das formas de transformar a educação (CARMARGO, 2018, p. 28).

Criar condições é acima de tudo explorar novas didáticas, a partir da nova realidade tecnológica o docente é instigado a pesquisar diferentes formas de obtenção de conhecimento em sala de aula. É uma atualização que objetiva redefinir a relação entre os professores e alunos, pois a contemporaneidade e a complexidade da técnica garantem inovadoras interações, a linguagem é redefinida:

A 'didática' da filosofia é uma construção (uma base conceitual teórica e prática) que deveria ter a vitalidade de atualizar-se todos os dias. Em cada atividade proposta, põe-se em jogo a relação que cada professor tem com o filosofar e seu ensino. Não seria admissível nem um ensinar nem um filosofar diante dos quais os próprios professores fossem mediadores passivos ou do qual se sentissem alheios (CERLETTI, 2009, p. 78).

Isso quer dizer que, as estratégias didáticas no ensino de filosofia devem ser acompanhadas com análises profundas sobre como o professor enxerga a inserção da tecnologia, como se comporta no manejo com ela e como pode modificar seu entendimento acerca dos conteúdos filosóficos: "[...] é preciso levar em conta os diversos fatores que contribuem para a configuração de um processo inovador, implicando a criatividade dos sujeitos, a motivação para efetivar ideias, o conhecimento e os recursos materiais possíveis" (CARMARGO, 2018, p. 30). Por isso, é de ser perceber que inovar na prática educacional requer questionamentos sobre as mudanças sugeridas, como uma reflexão de ação docente. Em virtude disso, ocorre uma transformação na prática docente, pois o ambiente virtual proporcionou ao professor a versatilidade em atividades e recursos para a realização da mediação de conhecimento, uma vez que o conhecimento é resultado de trocas que se estabelecem na interação entre o meio natural, social, cultural e o sujeito.

Ao repensar a forma docente no século XXI, é preciso estar atento ao contexto de inovação metodológica em curso e às demandas profissionais. [...] Requer-se, então, um novo perfil de docente, qualificado e capaz de atuar em cenários que estão em transformação. [...] A nova função docente exige foco na aprendizagem e conhecimento sobre as diversas maneiras de como se aprende nos cursos superiores, principalmente devido à infinidade de informações disponíveis. A prática docente está adaptando aos novos formatos de produzir conhecimentos, rompendo com a tradicional aula expositiva, propondo desafios e fazendo pensar, um contraponto em relação à reprodução e à memorização, formatos educativos vigentes no país (DEBALD, et al., 2020, p. 72).

A dinâmica proporcionada pelas tecnologias digitais no ensino permite uma maior diversidade em exposição de conteúdos e na forma como os estudantes interagem com o tema estudado. A aprendizagem ganha movimento, isto é, o aluno é instigado a aprender de maneiras diversas, criando uma interação cognitiva: "Portanto, a diversidade de materiais tem o papel de facilitar a aprendizagem, proporcionando ao estudante diferentes experiências pessoais de aprendizagem, adequando-as às necessidades para a sua compreensão" (DEBALD, et al., 2020, p. 73). Nesse sentido, o docente pode obter maior êxito na aprendizagem do discente, e diversificar os métodos de interação no espaço educacional: "[...] as práticas pedagógicas propostas pelas metodologias do ensino híbrido têm se disseminado nas redes de ensino de todo o mundo, por oferecer aos alunos acesso a um aprendizado interessante, eficiente e personalizado as suas necessidades reais" (CARMARGO, 2018, p. 31). Levando em consideração essas perspectivas, o professor de filosofia pode criar um ambiente de confiança, promovendo debates, discussões, questionamentos, críticas e reflexão. Além disso, outro desafio no ensino híbrido se faz importante mencionar: a capacitação dos professores, pois é necessário possuir condições necessárias para atuar em contextos inovadores de produção de conhecimento. Assim, o profissional de educação terá oportunidade de facilitar a 
aprendizagem dos discentes, é um processo que também envolve o desenvolvimento de tarefas relacionadas à gestão e a execução de inovadoras estratégias. De acordo com Debald et al. (2020), no ensino acadêmico, a adequação do modelo hibrido é mais fácil, devido a maturidade, direcionamento e especificidade de aprendizagem. Por isso, compreende-se que em relação ao ensino de filosofia nessa perspectiva:

A atitude filosófica coerente desejada, ao nosso ver, será de compreender, desde uma perspectiva filosófica, a educação. A própria natureza da educação exige uma reflexão crítica e, já, a filosofia, ao tomar a educação como objeto de suas indagações estará filosofando (GALLO, CORNELLI, DANELON, 2003, p. 181).

Portanto, percebe-se que a sala de aula precisa adaptar-se às rotinas ligadas às tecnologias, o ensino híbrido é inserido forçosamente no contexto educacional durante a pandemia, e passa a ser o principal ponto de comunicação nas instituições educacionais. Dessa maneira, alunos e professores têm a possibilidade de trocarem informações e experiências, possibilitando trabalhos individuais, e em grupo por intermédio de debates e fóruns.

Para o trabalho pedagógico por meio do ensino híbrido, os professores podem contar com vários tipos de programas [...] que compõem um cenário tecnológico no ambiente educativo, como os de realidades mistas (realidade aumentada e visualidade aumentada), realidade virtual, tecnologias mobile, plataformas digitais de busca, plataformas adaptativas, games e entretenimento, tecnologias inteligentes de voz, vídeos digitais e Qrcodes (CARMARGO, 2018, p. 113).

Por esse motivo, nota-se que há uma necessidade de transformação do método de aprendizagem, e o cenário epidêmico mostrou que é possível uma adaptação docente nesse sentido: "A descentralização do papel docente como transmissor do conteúdo para mediador o colocou numa relação de horizontalizada com o discente, o que exacerba a percepção do professor para as necessidades individuais de aprendizagem e de vocação de aluno" (DEBALD, et al., 2020, p. 78). Sendo assim, é preciso compreender a nova relação que o ensino híbrido evoca na docência, ou seja, entender a dinâmica do perfil que o professor tem nas modalidades ativas de conhecimento.

\section{METODOLOGIA}

Averiguar o ensino de Filosofia em tempos de pandemia, dentro do contexto de aula remota e como os docentes do ensino superior lidam com essa nova configuração diante desses ambientes virtuais requer procedimentos metodológicos específicos. Dessa forma com o objetivo em elucidar as questões que norteiam a problematização desta pesquisa alguns percursos são necessários para compreender os parâmetros deste trabalho. Quanto aos objetivos é uma pesquisa descritiva, pois buscou explanar as habilidades, concepções e experiências dos professores dos cursos de Filosofia das universidades públicas do estado do Maranhão. Esses relatos foram coletados por meio de um questionário on-line distribuído para os docentes, contendo 10 questões relativas ao formato da sala de aula e o contexto pandêmico. No tocante ao procedimento técnico é uma pesquisa que possui o caráter de levantamento, pois se justifica na medida em que possui em seu escopo um nicho específico de profissionais e encontrar definições significativas sobre o problema em evidencia neste artigo. Nesse caso compreender como os educadores estão se comportando diante desse período e como observam o ensino remoto e virtual. De acordo com Gil (2008. p.30):

[...] é a interrogação direta das pessoas cujo comportamento se deseja conhecer. Procede-se à solicitação de informações a um grupo significativo de pessoas acerca do problema estudado para, em seguida, mediante análise quantitativa, obterem-se as conclusões correspondentes aos dados coletados. Quanto o levantamento recolhe informações de todos os integrantes do universo pesquisado, tem-se um censo.

Com isso faz-se necessário à pontuação de dois parâmetros que nortearam essa pesquisa:

Parâmetro 1: Traçar o perfil dos professores de Filosofia que responderam o questionário, suas experiências na sala de aula on-line, que tipo de professor ele e suas conjecturas dentro do processo de ensino-aprendizagem no formato de aula remota.

Parâmetro 2: Elucidar a frequência com que eles lidam com as tecnologias digitais dentro desse ambiente virtual, além das concepções em ensinar por meio da tela digital e as interferências encontradas nesse meio.

Diante dessa perspectiva essa pesquisa é de caráter qualitativa e quantitativa uma vez que os dados analisados serão numéricos, diante das perguntas realizadas no questionário. Essa combinação cientifica foi necessária na medida em que tenta compreender e explicar o fenômeno proposto nesta pesquisa e ela serve de instrumento para entender, descrever, classificar e explicar fenômenos e a relação existente entre as variáveis. Por outro lado, a técnica quantitativa abordas as questões estatísticas e o processo investigativos dos dados coletados, que nesse caso, refere-se ao material coletado das respostas comentadas no questionário e como isso tem relação qualitativamente para os objetivos deste artigo.

Coleta de dados: A interpretação dos dados é fundamental para entender o intuito dos métodos propostos. Dessa forma foi realizado um questionário com 10 perguntas de natureza semiestruturada, com perguntas objetivas e dissertativas aos entrevistados. O foco da pesquisa foi destinado apenas a professores de Filosofia do ensino superior com titulação em Mestrado ou Doutorado vinculados em uma das três universidades públicas estaduais ou federais do estado do Maranhão, são elas: Universidade Federal do Maranhão (UFMA); Universidade Estadual do Maranhão (UEMA) e Instituto Federal do Maranhão (IFMA), e que necessariamente estivesse dando aula em ambientes de ensino remoto. Equivalente a isso o questionário foi respondido entre os dias 17 a 22 de março de 2021, concedendo tempo hábil para amostragem das respostas. Vale destacar que o questionário foi sistematizado por meio da plataforma do Formulário Google e difundido para o nicho proposto. Com o objetivo de tentar traçar quem é esse docente, seu perfil, faixa etária, instituição e titulação inferiu-se que: 11 professores responderam a entrevista, dessa forma, o professor de Filosofia do curso superior que participou da pesquisa tem entre 28 a 52 anos e a maioria contabiliza $63,6 \%$ que possui o título de doutor e $36,4 \%$ é mestre. Dentro desse universo em relação ao vínculo com a instituição $18,2 \%$ são ligados ao IFMA; $27,3 \%$ à UEMA e o maior número corresponde a $54,5 \%$ da UFMA.

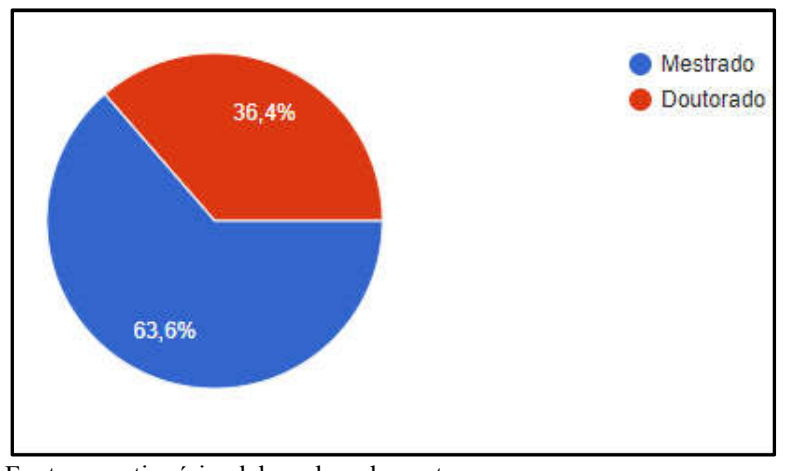

Fonte: questionário elaborado pelos autores

\section{Figura 1. Titulação dos docents}

Questionados sobre qual plataforma utilizam para dar aula o Google Meet foi à resposta mais respondida pelos educadores. Sobre as dificuldades com o formato de aula on-line, a prevalência de uma resposta positiva sobressaiu em meio às alternativas "não" e "às 
vezes". Sendo assim, 54,5\% responderam que 'sim', lidam com estorvos nesse modelo de aula virtual. Por outro lado, 18, 2\% alegaram que não sentem dificuldades, enquanto $27,3 \%$ afirmaram que os percalços são esporádicos. Em relação a que tipo de dificuldades se refere ficou um empate entre a opção "problemas de conexão (internet) e "'outras" intervenções, ambas com o quantitativo de $36,4 \%$. O restante das alternativas foi dividido entre estorvos com estrutura da plataforma e ambiente externo como barulhos e interferências sonoras.

2. Diante dessa pandemia tem sentido dificuldades no formato de aula on-line? 11 respostas
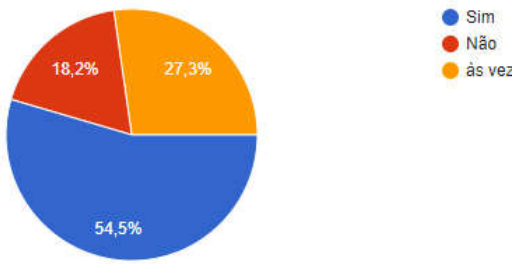

às veze

Fonte: questionário elaborado pelos autores

\section{Figura 2. Quantitativo dificuldades no formato on-line}

No tocante à constância dos docentes ao modelo de sala de aula virtual, $100 \%$ dos entrevistados responderam que não estavam acostumados com o formato do ensino remoto antes da pandemia. Questionados sobre com que frequência utiliza outros recursos didáticos (aplicativos, redes sociais, canais de comunicação) como tecnologias digitais para dar aula, 45, 5\% alegaram que 'quase nunca' utilizam essas ferramentas em aula. Sobre a probabilidade de usarem esses suportes 36, 4\% atestaram que sempre que possível aplicam na sala de aula; por outro lado $18,2 \%$ afirmaram que usam constantemente.

8. Com que frequência utiliza outros recursos didáticos (aplicativos, redes sociais, canais de comunicação) como midias digitais para dar aula?

11 respostas
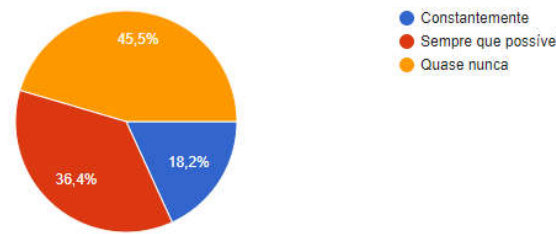

Fonte: questionário elaborado pelos autores

Figura 3. Frequência que utilizam recursos digitais

9. Você percebeu algum baixo desempenho dos alunos nesse formato de aula remota? Cite quais.
11 respostas
Sim, além da desistência de alguns, percebi um menor empenho na leitura dos textos.
Ainda não
Sim. Disposição para as aulas. Ficam mais introspectivos, não participam.
o ensino a distância dificulta até mesmo esse diagnóstico. Mas a principal baixa é a dificuldade de
manter o foco.
A disposição para participar das aulas, bem como o entusiasmo perante as aulas ministradas foram
fortemente afetados.
Baixa interatividade, apatia, dificuldade de acompanhar a leitura.
Dificuldades com acesso à internet, desânimo, dificuldades em participar das aulas.

Alguns estudantes têm dificuldade de acesso a internet, o que gera dificuldade no envio das atividades.

Fonte: questionário elaborado pelos autores

Figura 4. Perguntas abertas sobre desempenho dos alunos no ensino remote
A parte do questionário revelou quesitos pertinentes sobre o desempenho no formato de aula remota e as principais reclamações dos discentes sobre esse modelo. Em relação ao primeiro, a maioria dos professores relatou desestímulo, problemas com internet, exaustão, baixa interatividade dentre outros pontos (veja abaixo). $\mathrm{O}$ segundo quesito sobre o feedback dos alunos a concepção do ensino remoto a partir do olhar do professor, muitos ressaltaram dificuldades técnicas com a internet, ausência do contato presencial e cansaço em ficar horas olhando para a tela digital. Dessa forma compreende-se a baixa autoestima e interesse dos alunos por meio desse formato, pela falta do contato físico, por horas de aula na plataforma on-line e a prevalência majoritária de problemas técnicos com a operadora de internet. Veja abaixo:

\section{CONSIDERAÇÕES FINAIS}

Com este estudo, objetivamos demonstrar como professores de filosofia do ensino superior público estavam lidando com o ensino remoto nas instituições. A perspectiva da pesquisa teve o intuito de analisar o comportamento docente mediante o cenário proporcionado pela COVID-19 no Brasil. A pandemia iniciada em 2020 exigiu uma mudança de comportamento da sociedade como um todo e não foi diferente na área da educação. Porém, esse quadro epidêmico exigiu uma alteração abrupta nas habilidades pedagógicas dos professores, o espaço virtual ainda pouco explorado passou a ser fonte única de comunicação com os discentes e, novas competências passaram a ser exigidas. Além do mais, foi possível observar que esse novo contexto expôs desigualdades sociais, pois o acesso à internet e a aparelhos eletrônicos como computador, notebook, ipad e smartphones é limitado, e longe do alcance de muitas pessoas, o que consequentemente prejudica a qualidade de ensino. No entanto, é importante destacar que, o ensino remoto é realidade em boa parte das universidades, mas não tinha alcançado o espaço que acabou conquistando devidos os problemas causados pelo quadro pandêmico mundial. Nesse sentido, houve a necessidade de se avaliar os pontos positivos que essa forma de educação proporciona para a educação. As capacidades exigidas no espaço virtual são em muitos pontos eficazes, tendo em vista que explora a aprendizagem sob várias perspectivas e estabelece uma outra dinâmica de comunicação entre os personagens educacionais. Nesse ínterim, a Filosofia como disciplina desenvolve reflexões acerca da educação e a relação com as tecnologias digitais. O panorama educacional muda, mas o papel do docente em filosofia permanece o mesmo, que é pensar em inovadoras didáticas que incentivem os alunos ao exercício da autonomia pessoal. A personalização da aprendizagem do ensino remoto proporciona expansivas formas de linguagem, aumentando o leque de interações dos professores com os estudantes.

Mediante esse entendimento foram traçados perfis dos professores de filosofia com o objetivo de compreender como lidam com o ensino remoto. A partir disso, fora analisado as respostas de questionário de 10 perguntas, sendo duas delas de caráter subjetivo e que foram respondidas por 11 docentes do ensino superior público do Maranhão (UFMA, UEMA, IFMA), com qualificações de mestrado e doutorado. Assim, dados estatísticos foram averiguados para entender a forma como esses profissionais estão lidando com a educação à distância, além disso é importante ressaltar que a pesquisa teve como plataforma de estudo o formulário google, ferramenta prática para atividades dessa natureza. $\mathrm{O}$ perfil de idade entre os profissionais variou de 28 a 52 anos e a maioria possuía a titulação de doutorado, sendo de $63,6 \%$ contra 36,45 de docentes com título de mestrado. A maior parte entre os participantes do estudo são ligados a UFMA, vindo seguida da UEMA e por último do IFMA. Com base nisso, foi possível observar que a maior parte dos professores utilizam a plataforma Google Meet para ministrar às aulas e a maioria mostrouse com dificuldades no ensino remoto, sendo que $54,5 \%$ responderam que lidam com problemas durante as aulas virtuais, 27, 3\% afirmaram ter problemas esporádicos e 18,2\% responderam que não possuem contratempos em relação a essa modalidade de ensino. Entre os inconvenientes citados pelos participantes da pesquisa as respostas ficaram divididas entre "problemas de conexão" e "outras" 
intervenções. Contudo, alguns desses profissionais mostraram-se insatisfeitos com a funcionalidade da plataforma e com interferências sonoras dos ambientes. Essas e outras objeções mostram-nos que o ensino virtual ainda é apresentado de modo tímido nessas universidades, pois $100 \%$ dos entrevistados responderam que antes da pandemia nunca tinham lidado com o formado de aulas on-line. $\mathrm{O}$ que explica a consequente baixa adesão destes em relação ao uso de recursos didáticos virtuais, correspondendo a uma negativa de $45,5 \%$, em seguida, 36,4\% atestaram que utilizam aplicativos de vez em quando e $18,2 \%$ afirmaram usar constantemente meio digitais nas aulas.

A pesquisa evidenciou ainda o desempenho do formato das aulas remotas para os profissionais entrevistados e quais eram as principais reclamações do discentes. Notou-se através das respostas que os docentes se sentem desestimulados com o formato devido a exaustão, problemas com conexão e baixa interatividade, sendo essa última um grande problema para a disciplina de Filosofia. Pois o diálogo em uma aula de filosofia é fundamental, é o que permite que o professor estabeleça horizontes para o estudo filosófico e proponha dinâmicas características da disciplina com os estudantes, ou seja, ter uma visão dialética com os assuntos estudados. Por outro lado, os docentes afirmam que os alunos ficam dispersos devido ao cansaço, problemas técnicos e pela falta de contato presencial. Portanto, a partir do que fora analisado por intermédio do questionário, é relevante pontuar que a pandemia, de forma abrupta, acentuou a necessidade de se explorar outras formas de ensino nas universidades. É verdade que há uma preferência quase inquestionável pelo ensino presencial, contudo, faz-se necessário preparar os profissionais para lidar com as mais diversas situações, que vão desde o trato com as ferramentas digitais, até a forma de reinventar didaticamente à sala de aula. Perspectiva semelhante espera-se dos alunos, uma vez que são agentes importante nessa mudança de ciclo, e estes também deveriam ser preparados para obter um aproveitamento adequado nas aulas remotas. Nesse ínterim, a filosofia surge como um fator relevante para pensar essa nova realidade, refletir como lidar com o espaço virtual e desenvolver-se juntamente com as metodologias ativas. Portanto, o presente estudo demonstrou a necessidade de raciocinar sobre essa nova perspectiva, que devido a pandemia, passou a ser comum na realidade da educação. Além disso, este trabalho não teve intenção de trazer diagnósticos definitivos e sabemos que o decorrer do cenário pandêmico pode-nos oferecer outras respostas.

\section{REFERÊNCIAS BIBLIOGRÁFICAS}

CARMARGO, Fausto. A sala de aula inovadora [recurso eletrônico]: estratégias pedagógicas para fomentar o aprendizado ativo / Fausto Camargo, Thuinie Daros. Porto Alegre: Penso, 2018.

CERLETTI, A. O ensino de filosofia como problema filosófico. Tradução de Ingrid Müller Xavier. Belo Horizonte: Autêntica, 2009.

CUPANI, Alberto. Filosofia da tecnologia : um convite / Alberto Cupani. 3. ed. - Florianópolis: Editora da UFSC, 2016.

DEBALD, Blasius. et al. Metodologias ativas no ensino superior : o protagonismo doaluno [recurso eletrônico] / Organizador, Blasius Debald. - Porto Alegre : Penso, 2020.

GALLO, S. Metodologia do Ensino de Filosofia. Editora: Papirus, 2014.

GALlO, Silvio; CORNELlI, Gabriele; DANELON, Márcio. Filosofia do ensino de filosofia. -Petropólis, RJ: Vozes, 2003.

GIL, Antonio Carlos. Como elaborar projetos de pesquisa. 4. ed. São Paulo: Atlas, 2008.

JUNIOR, J.B, Sala de Aula Invertida: Recomendações e Tecnologias Digitais para suaImplementação na Educação. Revista Renote. v.17, p.1-11, 2019. Disponível em: https://seer.ufrgs.br/renote/article/view/96583/54183. Acesso em: 10 mar 2021.

KENSKI, Vani Moreira. Tecnologias e ensino presencial e a distância. $6^{\mathrm{a}}$ ed.

LÉVY, Pierre. Cibercultura. São Paulo: Editora 34, 2000.

MEC.2020. Portaria 343. 17.03.2020. Brasília. Disponível em: http://www.crub.org.br/blog/mec-publica-a-portaria-39520-eprorroga-as-aulasremotas-no-sistema-federal-de-ensinosuperior/. Acesso em: 18 março 2021.

QUINTAS-MENDES, Antonio et al. Comunicação mediatizada por computador e educação on-line: da distância à proximidade. In: SILVA, Marco et al (orgs.). Educação on-line: cenário, formação e questões didáticometodológicos. Rio de Janeiro: Walk, 2010.

QUINTAS-MENDES, Antonio et al. Comunicação mediatizada por computador e educação on-line: da distância à proximidade. In: SILVA, Marco et al (orgs.). Educação on-line: cenário, formação e questões didáticometodológicos. Rio de Janeiro: Walk, 2010.

TALBERT, ROBERT. Guia para utilização da aprendizagem invertida no ensino superior. Porto Alegre: Penso, 2019. 